\title{
Treatment of Lead Poisoning \\ A Comparison between the Effects of Sodium Calciumedetate and Penicillamine Administered Orally and Intravenously ${ }^{1}$
}

\section{STIG SELANDER}

From Medical Service I, Sahlgrenska Sjukhuset, University of Göteborg, Göteborg, Sweden

In 16 workers with lead poisoning of varying degrees, a comparison was made between the therapeutic efficacy of sodium calciumedetate (Ca-EDTA) and penicillamine (PCA), administered intravenously and orally. The question of comparable dosages of ligands, forming metal complexes in different ways, is discussed. With the dosages given, intravenous Ca-EDTA promoted the greatest output of lead in the urine, followed by intravenous and oral PCA. These three agents also had a very satisfactory effect on the output of $\delta$-aminolaevulinic acid (ALA) in urine. Oral Ca-EDTA was found to be greatly inferior in both these respects.

In order to study the absorption of the agents and the renal excretion of the formed lead complexes, the urine was collected quantitatively and fractionated in consecutive 4-hour periods, after which the lead excretion during each period was determined. It was found that the oral absorption of PCA was rapid and quantitatively great, whereas the oral absorption of Ca-EDTA was very slow and quantitatively small. The possible resorption of ligand-lead complexes is discussed and indications were found of resorption of the Ca-EDTA-lead complex but not of the PCA-lead complex. The renal excretion of the differento ligand-lead complexes was very effective and reached its maximal level within four hours. However, in some subjects excretion of the Ca-EDTA-lead complex showed some delay. An investigation, in four $\bigodot^{\circ}$ subjects, of a blocking effect of probenecid on the renal excretion of PCA and/or PCA-lead complexes gave no conclusive results. It is concluded that oral PCA is satisfactory in most cases of lead poisoning. However, in more severe cases intravenous treatment is preferable. Which agent should be chosen, Ca-EDTA or PCA, appears to be unimportant as both are quite satisfactory from the point of view of treatment, but it seems that Ca-EDTA may cause more serious side-effects. Oral Ca-EDTA is quite unsatisfactory and there is good evidence to indicate that the agent causes a resorption of Ca-EDTA-lead complexes from the gastro-intestinal tract.

Intravenous sodium calciumedetate (Calcium Disodium Versenate-Ca-EDTA) and oral penicillamine (PCA) have been proved to be effective in the treatment of lead poisoning (Bessman, Ried, and Rubin, 1952; Foreman, Hardy, Shipman, and Belknap, 1953; Rieders, Dunnington, and Breiger, 1955; Teisinger and Srbová, 1956; Boulding and Baker, 1957; Harris, 1958; Leckie and Tompsett, 1958; Ohlsson, 1962; Perol, Graveleau, Potter, and Morin, 1962; Goldberg, Smith, and Lockhead, 1963; Moncrieff, Koumides, Clayton, Patrick, Renwick, and Roberts, 1964; Caccuri and Pecora,

Received for publication March 15, 1967.

1This work was supported by grant No. $W_{366}+$ B676IP-2094-0I from the Swedish Medical Research Council and grants from Försäkringsföretaget Fölksam.
1965; Selander, Cramér, and Hallberg, 1966). Isolated cases have been reported in which PCA has been given intravenously with good results and without side-effects (Haeger-Aronsen, 1960; Ohlsson, 1962). Opinions on the efficacy of oral Ca-EDTA are divergent, despite the fact that it has been clearly shown that the agent is very poorly absorbed (only between 2 and $5 \%$ ) from the gastrointestinal tract (Srbová and Teisinger, 1957; Foreman, 1960). Thus, some authors maintain that it is effective (Manville and Moser, 1955; Bell, Gilliland, Boland, and Sullivan, 1956; Williams, Matthews, and Judd, 1962), whereas others consider oral Ca-EDTA to be contraindicated because it increases the absorption of lead from the gut and in this way can even precipitate or increase the symptoms of poisoning (Kehoe, 1955; Rieders and Breiger, 1955; Byers, 1959b; Rieders, 1960). 
There are few comparisons in the literature between the agents and the various methods of administration and the results are contradictory (Sidbury, Bynum, and Fetz, I953; Harris, 1958; Mosser and Bessman, 1960; Ohlsson, 1962, 1963; Moncrieff et al., 1964; Caccuri and Pecora, I965). Therefore, the purpose of the present work was to make a comparative study in a number of hospital in-patients, since uniform treatment and careful supervision were possible, especially the quantitative collection of urine.

The possibility that probenecid might block the urinary excretion of PCA, in the same way that it blocks the tubular excretion of some organic acids, was also studied.

\section{Material}

Sixteen patients with varying degrees of lead poisoning were included in this study. Their occupational and clinical histories are summarized in the Appendix (p. 282). Laboratory data obtained before treatment are given in Table I.

Lead poisoning was discovered at prescribed medical examinations except in case IX, who came to the hospital of his own accord because of symptoms. Thus, the laboratory data of this patient show the condition only a day or two after the last exposure to lead, whereas the interval between exposure and treatment was greater in the other patients. The patients were allocated to the treatment schedules in the order in which they were admitted to hospital, so that the first patients were put in the first treatment group and so on.

In addition to the values given in Table $I$, it should be mentioned that sternal puncture was performed in seven patients (V, VI, VIII, IX, X, XI, and XII) and revealed a toxic influence on the myelopoietic system, an increased erythropoiesis, and basophilic stippling. The changes were of varying degrees but of the same type in all the patients.

\section{Methods}

Laboratory Methods In this study the same laboratory methods and normal values were used as were described previously (Cramér and Selander, 1965; Selander et al., 1966).

Plan of Study Initial laboratory studies were performed during the first 24 to 48 hours after admission. The patients were instructed to collect their urine quantitatively.

Treatment was given in three different schedules in order to compare the therapeutic effect of (I) oral PCA, oral Ca-EDTA, and intravenous Ca-EDTA, (2) oral PCA and intravenous PCA, and (3) intravenous PCA and intravenous Ca-EDTA. The treatment schedules and the number of patients in each group are shown in Table I. Within the groups the treatment was started alternately with the agents which were to be compared, so as to correct for the effect of a diminishing excretion of lead during the course of treatment. The first group is

TABLE I

Initial Laboratory Data, Total Lead OUtput DuRing Therapy, and Therapy Schedules

\begin{tabular}{|c|c|c|c|c|c|c|c|c|}
\hline Patient & $\begin{array}{c}A L A \\
(m g \cdot / \text { roo } \mathrm{ml} . \\
\text { urine) }\end{array}$ & \multicolumn{2}{|c|}{$\begin{array}{c}\text { Lead } \\
(\mu g \cdot / \text { roo ml.) } \\
\text { Blood Urine }\end{array}$} & $\begin{array}{c}\text { Punctate } \\
\text { Basophils } \\
\text { (per IO,OOO } \\
\text { R.B.C.) }\end{array}$ & $\begin{array}{c}\mathrm{Hb} \\
(\mathrm{g} \cdot / \mathrm{IOO} \mathrm{ml} .)\end{array}$ & $\begin{array}{l}\text { Diuresis during } \\
\text { first } 24 \text { hrs } \\
\text { (ml.) }\end{array}$ & $\begin{array}{l}\text { Excretion of } \\
\text { Lead during } \\
\text { Therapy (mg.) }\end{array}$ & $\begin{array}{c}\text { 6-day } \\
\text { Therapy Schedules }\end{array}$ \\
\hline I & $2 \cdot 21$ & 60 & 18 & 0 & $12 \cdot 8$ & I,290 & $I I \cdot I 6$ & $P_{\circ} P_{\circ} E_{\circ} E_{0} E_{1} E_{1}$ \\
\hline II & $3 \cdot 33$ & 45 & 22 & $\mathbf{I}$ & $12 \cdot 7$ & 985 & $9 \cdot 71$ & $P_{0} P_{0} E_{0} E_{0} E_{1} E_{1}$ \\
\hline III & $2 \cdot 02$ & 40 & 13 & 0 & $14 \cdot 6$ & 1,370 & $8 \cdot 30$ & $P_{\circ} P_{\circ} E_{0} E_{0} E_{1} E_{1}$ \\
\hline IV & $I \cdot 27$ & 60 & 13 & 0 & $13 \cdot 1$ & 1,280 & $6 \cdot 11$ & $P_{0} P_{0} E_{0} E_{0} E_{1} E_{1}$ \\
\hline V & $3 \cdot 39$ & 80 & 42 & 5 & $13 \cdot 8$ & 1,220 & 13.58 & $E_{0} E_{0} P_{0} P_{0} E_{1} E_{1}$ \\
\hline VI & $4 \cdot 06$ & 55 & 23 & 4 & $I I \cdot 4$ & 1,360 & $12 \cdot 93$ & $E_{0} E_{0} P_{0} P_{0} E_{1} E_{1}$ \\
\hline VII & $3 \cdot 76$ & 60 & I I & 9 & I I $\cdot 0$ & I,273 & $10 \cdot 15$ & $E_{\circ} E_{0} P_{\circ} P_{0} E_{1} E_{1}$ \\
\hline VIII & - & 65 & 22 & 0 & $\mathbf{I 2} \cdot \mathbf{I}$ & 780 & $8 \cdot 66$ & $E_{0} E_{0} P_{0} P_{0} E_{1} E_{1}$ \\
\hline IX & $5 \cdot 06$ & 100 & 38 & 4 & $\mathbf{I} \mathbf{I} \cdot \mathbf{I}$ & I,535 & $35 \cdot 33^{\star}$ & $P_{1} P_{0} P_{1} P_{\circ}\left(P_{o p} P_{o p}\right)$ \\
\hline $\mathbf{X}$ & $7 \cdot 00$ & 75 & 55 & 34 & $9 \cdot 6$ & 1,250 & $19 \cdot 72^{\star}$ & $P_{1} P_{o} P_{1} P_{o}\left(P_{o p} P_{o p}\right)$ \\
\hline $\mathbf{X I}$ & $7 \cdot 26$ & - & 27 & I4 & II $\cdot 2$ & 710 & $16 \cdot 93^{\star}$ & $P_{o} P_{1} P_{o} P_{1}\left(P_{o p} P_{o p}\right)$ \\
\hline XII & $5 \cdot 18$ & 80 & 46 & 4 & $13 \cdot 6$ & 780 & I I $15^{\star}$ & $P_{o} P_{1} P_{o} P_{1}\left(P_{o p} P_{o p}\right)$ \\
\hline XIII & $2 \cdot 72$ & 75 & 2 I & 50 & $14 \cdot 2$ & 2,420 & $21 \cdot 83$ & $P_{1} E_{1} P_{1} E_{1} P_{1} E_{1}$ \\
\hline XIV & $3 \cdot 85$ & 50 & 29 & 4 & $14 \cdot 5$ & 780 & $12 \cdot 85$ & $P_{1} E_{1} P_{1} E_{1} P_{1} E_{1}$ \\
\hline XV & $5 \cdot 56$ & 80 & 44 & IO & $15 \cdot 7$ & I,070 & 20.99 & $E_{1} P_{1} E_{1} P_{1} E_{1} P_{1}$ \\
\hline XVI & $I \cdot 78$ & 70 & 29 & $\mathbf{I}$ & $15 \cdot 5$ & I, I90 & $8 \cdot 33$ & $E_{1} P_{i} E_{1} P_{1} E_{1} P_{1}$ \\
\hline
\end{tabular}

*During the first four days of therapy.

$\left(\mathbf{P}_{0}=\right.$ oral PCA; $\mathbf{P}_{1}=$ intravenous $\mathbf{P C A} ; \mathbf{P}_{\mathrm{op}}=$ oral $\mathrm{PCA}+$ probenecid; $\mathrm{E}_{0}=$ oral Ca-EDTA; $\mathrm{E}_{1}=$ intravenous Ca-EDTA. These symbols are used throughout the tables and figures.) 
an exception to this in that in all cases the treatment ended with intravenous Ca-EDTA. The dosage was the same, I g. at 7 a.m. and I g. at 7 p.m., for both the agents as was the method of administration. Oral PCA was given as capsules containing $250 \mathrm{mg}$. and, for intravenous injection, a $5 \%$ solution was prepared from the substance supplied by Merck, Sharpe, and Dohme, Inc. Ca-EDTA was given intravenously as a $10 \%$ solution and the same solution was also used orally, in order to obtain optimal conditions for absorption.

The possibility that probenecid might have a blocking effect on the excretion of PCA was investigated in treatment group 2. After four days' treatment with oral and intravenous PCA alternately, the treatment in these four cases was continued for two days with oral PCA together with 2 g. probenecid daily (Table I).

Within the three treatment groups the effects of the different agents and methods of administration on lead excretion were estimated by comparing the means of their percentage share of the total lead excretion (Table III and Fig. I).

During the whole course of treatment in groups 2 and 3 , and during the first four or five days in group $I$, the urine was collected in consecutive periods of four hours, starting at 7 a.m. However, the two periods during the night were combined to one period of eight hours between II p.m. and 7 a.m. At the end of each period the patients emptied the bladder before starting the collection of urine for the next period. The lead excretion during each period was determined. For the different types of treatment the means of the excretions during the periods were calculated, expressed as a percentage of the 24-hours' excretion. The purpose was to investigate the variations within the 24-hours' lead excretion during treatment with the different agents in order to obtain information about their absorption and excretion in the urine as lead-complexes.

The urinary output of $\delta$-aminolaevulinic acid (ALA) was followed daily. The concentration of lead in whole blood was determined before and after treatment and, in order to reveal possible side-effects, the tests described in a previous paper were performed (Selander et al., I966).

\section{Results}

Efficiency in Promoting Lead Excretion The results are given in Tables II and III and in Figure I. Table II shows the amount of lead excreted during each day of treatment and the total for each patient. Table III shows for the three treatment groups, the means for the percentage of lead excretion for which the different agents were responsible. The levels of significance for the differences between the means within each group are also given. Figure I shows the different effects on lead excretion. It is evident that the effect of oral PCA was superior to that of oral Ca-EDTA no matter which agent began the treatment $(P<0 \cdot 001)$. On the other hand, intravenous Ca-EDTA promoted a greater lead excretion than oral PCA, in spite of the

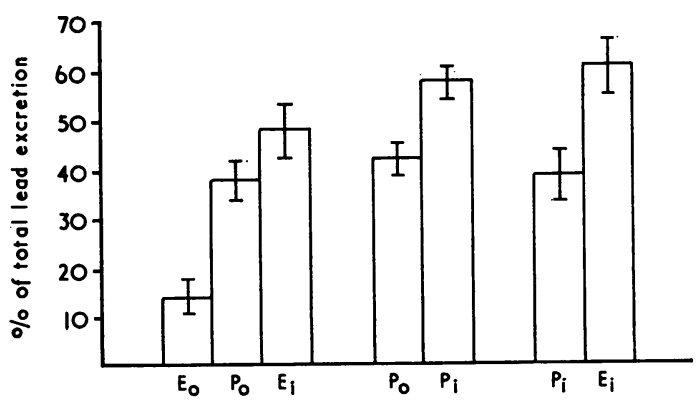

Fig. I. Effects on lead excretion of different agents within the three therapy schedules. The standard deviations are indicated.

fact that the former was always used at the end of treatment $(P<0.001)$.

The comparison between the effects of oral and intravenous PCA showed a greater lead excretion after intravenous therapy $(P<0.001)$. Finally, in the third treatment group intravenous Ca-EDTA caused a greater lead excretion than intravenous PCA $(\mathbf{P}<0.001)$.

The variations in the 24-hours' lead excretion during treatment with the different agents are shown in Figure 2. The means for lead excretion during the different periods of diuresis, expressed as a percentage of the total daily excretion, and tests of the differences between the means, are given in Table IV.

Intravenous therapy with Ca-EDTA and PCA had a very similar and regular effect on lead excretion, with pronounced maxima and minima during the 24 hours. After each dose there was a striking peak of lead excretion within four hours, and the smallest excretion was noted after eight to I2 hours. As mentioned previously, the two periods of diuresis during the night were combined into one period of eight hours between II p.m. and 7 a.m., which explains why the same means for lead excretion are given during these two 4-hour periods. In fact excretion during the period between I I p.m. and 3 a.m. was probably higher and that during the period between 3 and 7 a.m. lower than the calculated mean for the whole 8-hour period.

In two respects the effects of the agents were somewhat different. Thus, the second injection, at 7 p.m., gave a more pronounced maximum after PCA than after Ca-EDTA. The difference is significant $(P<0.05)$. Further, on some occasions a delay in lead excretion was observed after the injection of Ca-EDTA, so that it did not reach the maximal level until four to eight hours after the dose at 7 a.m., but such a delay never occurred 
TABLE II

Daily Output of Lead During Therapy. Effect of Therapy on Ala Concentration in the Urine

\begin{tabular}{|c|c|c|c|c|c|c|c|c|c|c|c|c|c|c|c|}
\hline \multirow{2}{*}{$\begin{array}{l}\text { Patient } \\
\text { Therapy }\end{array}$} & \multicolumn{7}{|c|}{$\begin{array}{c}\text { Excretion of Lead before and during Therapy } \\
\text { (mg./24 hrs) }\end{array}$} & \multirow[t]{2}{*}{$\begin{array}{l}\text { Total } \\
\text { (mg.) }\end{array}$} & \multicolumn{7}{|c|}{$\begin{array}{c}A L A \text { in Urine before and during Therapy } \\
(\mathrm{mg} . / 100 \mathrm{ml} .)\end{array}$} \\
\hline & O & $\mathbf{P}_{0}$ & $P_{0}$ & $\mathbf{E}_{\circ}$ & $E_{0}$ & $E_{1}$ & $\mathbf{E}_{1}$ & & $\mathbf{O}$ & $\mathbf{P}_{0}$ & $\mathbf{P o}_{0}$ & $\mathbf{E}_{0}$ & $\mathbf{E}_{\mathbf{0}}$ & $\mathbf{E}_{1}$ & $E_{1}$ \\
\hline $\begin{array}{l}\text { I } \\
\text { II } \\
\text { III } \\
\text { IV }\end{array}$ & $\begin{array}{l}0.23 \\
0.22 \\
0.18 \\
0.17\end{array}$ & $\begin{array}{l}2 \cdot 14 \\
1 \cdot 90 \\
1 \cdot 83 \\
I \cdot 12\end{array}$ & $\begin{array}{l}1 \cdot 99 \\
2 \cdot 20 \\
1 \cdot 82 \\
0 \cdot 87\end{array}$ & $\begin{array}{l}0.73 \\
0.85 \\
0.62 \\
0.21\end{array}$ & $\begin{array}{l}0.69 \\
0.54 \\
0.58 \\
0.32\end{array}$ & $\begin{array}{l}3 \cdot 55 \\
2 \cdot 52 \\
2 \cdot 22 \\
2 \cdot 34\end{array}$ & $\begin{array}{l}2 \cdot 08 \\
1 \cdot 71 \\
1 \cdot 24 \\
1 \cdot 25\end{array}$ & $\begin{array}{r}I I \cdot 16 \\
9 \cdot 71 \\
8 \cdot 30 \\
6 \cdot 11\end{array}$ & $\begin{array}{l}2 \cdot 21 \\
3 \cdot 33 \\
2 \cdot 02 \\
1 \cdot 27\end{array}$ & $\begin{array}{l}1 \cdot 32 \\
2 \cdot 34 \\
1 \cdot 35 \\
0 \cdot 64\end{array}$ & $\begin{array}{l}0.52 \\
0.85 \\
0.55 \\
0.48\end{array}$ & $\begin{array}{l}0.37 \\
0.82 \\
0.55 \\
0.49\end{array}$ & $\begin{array}{l}0.47 \\
0.81 \\
0.59 \\
0.54\end{array}$ & $\begin{array}{l}0.52 \\
0.75 \\
0.37 \\
0.52\end{array}$ & $\begin{array}{l}0.36 \\
0.49 \\
0.22 \\
0.43\end{array}$ \\
\hline Therapy & $\mathbf{O}$ & $\mathbf{E}_{0}$ & $E_{0}$ & $\mathbf{P}_{0}$ & $\mathbf{P}_{0}$ & $\mathbf{E}_{\mathbf{1}}$ & $E_{1}$ & & $\mathbf{O}$ & $\mathbf{E}_{0}$ & $\mathbf{E}_{\mathrm{o}}$ & $\mathbf{P o}_{0}$ & Po & $E_{1}$ & $E_{1}$ \\
\hline $\begin{array}{l}\text { V } \\
\text { VI } \\
\text { VII } \\
\text { VIII }\end{array}$ & $\begin{array}{l}0.51 \\
0.32 \\
0.15 \\
0.17\end{array}$ & $\begin{array}{l}0.77 \\
1.30 \\
0.92 \\
0.72\end{array}$ & $\begin{array}{l}0.68 \\
1.05 \\
1.06 \\
0.91\end{array}$ & $\begin{array}{l}2 \cdot 79 \\
2 \cdot 20 \\
1 \cdot 91 \\
1 \cdot 86\end{array}$ & $\begin{array}{l}2 \cdot 58 \\
2 \cdot 52 \\
1 \cdot 42 \\
1 \cdot 30\end{array}$ & $\begin{array}{l}4 \cdot 03 \\
3 \cdot 52 \\
2 \cdot 93 \\
2 \cdot 22\end{array}$ & $\begin{array}{l}2 \cdot 74 \\
2 \cdot 36 \\
1 \cdot 92 \\
I \cdot 65\end{array}$ & $\begin{array}{r}13.58 \\
12.93 \\
10.15 \\
8.66\end{array}$ & $\begin{array}{l}3.39 \\
4.06 \\
3.76 \\
-\end{array}$ & $\begin{array}{l}3 \cdot 89 \\
4 \cdot 28 \\
2 \cdot 78 \\
I \cdot 90\end{array}$ & $\begin{array}{l}3 \cdot 15 \\
3 \cdot 88 \\
1 \cdot 76 \\
1 \cdot 60^{*}\end{array}$ & $\begin{array}{l}\mathrm{I} \cdot 98 \\
3.03 \\
0.89 \\
1 \cdot 87\end{array}$ & $\begin{array}{l}1 \cdot 17 \\
1 \cdot 01 \\
0.50 \\
0.61\end{array}$ & $\begin{array}{l}0.97 \\
0.73 \\
0.49 \\
0.86\end{array}$ & $\begin{array}{l}0.60 \\
0.52 \\
0.32 \\
0.71\end{array}$ \\
\hline Therapy & O & $\mathbf{P}_{1}$ & $\mathbf{P}_{\mathbf{o}}$ & $\mathbf{P}_{\mathbf{1}}$ & $\mathbf{P}_{\mathbf{0}}$ & $\left(\mathbf{P}_{\mathrm{op}}\right.$ & $\left.\mathbf{P}_{\text {op }}\right)$ & & $\mathbf{O}$ & $\mathbf{P}_{1}$ & $\mathbf{P o}_{0}$ & $\mathbf{P}_{\mathbf{1}}$ & $\mathbf{P}_{0}$ & $\left(\mathbf{P}_{\text {oD }}\right.$ & $\left.P_{o p}\right)$ \\
\hline$\underset{X}{\text { IX }}$ & $\begin{array}{l}0.58 \\
0.69\end{array}$ & $\begin{array}{r}\text { I I } \cdot 79 \\
5 \cdot 65\end{array}$ & $\begin{array}{l}9 \cdot 64 \\
4 \cdot 34\end{array}$ & $\begin{array}{l}9 \cdot 87 \\
6 \cdot 25\end{array}$ & $\begin{array}{l}4 \cdot 04 \\
3 \cdot 48\end{array}$ & $\begin{array}{l}(4.44 \\
(3.04\end{array}$ & $\begin{array}{l}3 \cdot 86) \\
3 \cdot 33)\end{array}$ & $\begin{array}{l}35 \cdot 33 \\
19 \cdot 72\end{array}$ & $\begin{array}{l}5.06 \\
7.00\end{array}$ & $\begin{array}{l}3.00 \\
4.58\end{array}$ & $\begin{array}{l}3 \cdot 01 \\
3 \cdot 22\end{array}$ & $\begin{array}{l}2 \cdot 14 \\
3 \cdot 77\end{array}$ & $\begin{array}{l}1 \cdot 31 \\
3 \cdot 04\end{array}$ & $\begin{array}{l}I \cdot 33 \\
2 \cdot 50\end{array}$ & $\begin{array}{l}0 \cdot 72 \\
1 \cdot 29\end{array}$ \\
\hline Therapy & O & $\mathbf{P}_{0}$ & $\mathbf{P}_{1}$ & $\mathbf{P}_{\mathbf{o}}$ & $\mathbf{P}_{\mathbf{1}}$ & $\left(\mathbf{P}_{\mathrm{op}}\right.$ & $\left.P_{o p}\right)$ & & O & $\mathbf{P}_{0}$ & $\mathbf{P}_{1}$ & $\mathbf{P}_{\mathbf{o}}$ & $\mathbf{P}_{1}$ & $P_{\text {op }}$ & $P_{o p}$ \\
\hline $\begin{array}{l}\text { XI } \\
\text { XII }\end{array}$ & $\begin{array}{l}0.19 \\
0.36\end{array}$ & $\begin{array}{l}4 \cdot 72 \\
2 \cdot 98\end{array}$ & $\begin{array}{l}5 \cdot 65 \\
4 \cdot 23\end{array}$ & $\begin{array}{l}3 \cdot 10 \\
1 \cdot 95\end{array}$ & $\begin{array}{l}3 \cdot 47 \\
2 \cdot 00\end{array}$ & $\begin{array}{l}(2 \cdot 67 \\
(1 \cdot 39\end{array}$ & $\begin{array}{l}I \cdot 80) \\
I \cdot 39)\end{array}$ & $\begin{array}{l}16 \cdot 93 \\
11 \cdot 15\end{array}$ & $\begin{array}{l}7 \cdot 26 \\
5 \cdot 18\end{array}$ & $\begin{array}{l}3 \cdot 37 \\
3 \cdot 00\end{array}$ & $\begin{array}{l}2 \cdot 11 \\
1 \cdot 03\end{array}$ & $\begin{array}{l}1 \cdot 03 \\
0 \cdot 88\end{array}$ & $\begin{array}{l}0.48 \\
0.76\end{array}$ & $\begin{array}{l}0.37 \\
0.50\end{array}$ & $\begin{array}{l}0.34 \\
0.46\end{array}$ \\
\hline Therapy & O & $\mathbf{P}_{\mathbf{i}}$ & $E_{1}$ & $\mathbf{P}_{\mathbf{1}}$ & $E_{i}$ & $\mathbf{P}_{1}$ & $E_{1}$ & & $\mathbf{O}$ & $\mathbf{P}_{1}$ & $E_{1}$ & $\mathbf{P}_{1}$ & $E_{1}$ & $\mathbf{P}_{\mathbf{1}}$ & $E_{1}$ \\
\hline $\begin{array}{l}\text { XIII } \\
\text { XIV }\end{array}$ & $\begin{array}{l}0.51 \\
0.23\end{array}$ & $\begin{array}{l}5 \cdot 62 \\
2 \cdot 28\end{array}$ & $\begin{array}{l}6 \cdot 20 \\
3 \cdot 97\end{array}$ & $\begin{array}{l}2 \cdot 60 \\
1 \cdot 55\end{array}$ & $\begin{array}{l}3.50 \\
2.02\end{array}$ & $\begin{array}{l}1 \cdot 56 \\
0.98\end{array}$ & $\begin{array}{l}2 \cdot 35 \\
2 \cdot 04\end{array}$ & $\begin{array}{l}21 \cdot 83 \\
12 \cdot 85\end{array}$ & $\begin{array}{l}2 \cdot 72 \\
3 \cdot 85\end{array}$ & $\begin{array}{l}I \cdot 92 \\
I \cdot 98\end{array}$ & $\begin{array}{l}0.86 \\
0.75\end{array}$ & $\begin{array}{l}0.44 \\
0.58\end{array}$ & $\begin{array}{l}0.35 \\
0.35\end{array}$ & $\begin{array}{l}0.16 \\
0.24\end{array}$ & $\begin{array}{l}0.17 \\
0.29\end{array}$ \\
\hline Therapy & O & $\mathbf{E}_{\mathbf{1}}$ & $\mathbf{P}_{\mathbf{1}}$ & $\mathbf{E}_{1}$ & $\mathbf{P}_{\mathbf{1}}$ & $E_{1}$ & $\mathbf{P}_{1}$ & & O & $\mathbf{E}_{\mathbf{i}}$ & $\mathbf{P}_{1}$ & $\mathbf{E}_{1}$ & $\mathbf{P}_{\mathbf{1}}$ & $\mathbf{E}_{1}$ & $\mathbf{P}_{\mathbf{1}}$ \\
\hline $\begin{array}{l}\text { XV } \\
\text { XVI }\end{array}$ & $\begin{array}{l}0.47 \\
0.35\end{array}$ & $\begin{array}{l}5 \cdot 73 \\
2 \cdot 74\end{array}$ & $\begin{array}{l}4 \cdot 42 \\
1 \cdot 33\end{array}$ & $\begin{array}{l}4 \cdot 39 \\
1 \cdot 64\end{array}$ & $\begin{array}{l}x \cdot 98 \\
0.56\end{array}$ & $\begin{array}{l}2 \cdot 58 \\
1 \cdot 26\end{array}$ & $\begin{array}{l}1 \cdot 89 \\
0.80\end{array}$ & $\begin{array}{r}20 \cdot 99 \\
8 \cdot 33\end{array}$ & $\begin{array}{l}5 \cdot 56 \\
1 \cdot 78\end{array}$ & $\begin{array}{l}3 \cdot 31 \\
0.80\end{array}$ & $\begin{array}{l}\mathbf{I} \cdot 10 \\
0 \cdot 26\end{array}$ & $\begin{array}{l}0.99 \\
0.27\end{array}$ & $\begin{array}{l}0.54 \\
0.17\end{array}$ & $\begin{array}{l}0.63 \\
0.18\end{array}$ & $\begin{array}{l}0.48 \\
0.28\end{array}$ \\
\hline
\end{tabular}

*Therapy interrupted for two days during which the ALA concentration increased to $2 \cdot 18 \mathrm{mg}$. $/ 100 \mathrm{ml}$.

TABLE III

Means of Different Agents' Percentage of Total Lead ExCRETION DuRINg THERAPy aND Test OF DifFerenCES BETWEEN THE MEANS

\begin{tabular}{|c|c|c|c|}
\hline Therapy & $\begin{array}{l}\text { No. of } \\
\text { Patients }\end{array}$ & $\begin{array}{l}\text { Per cent of Total } \\
\text { Lead Excretion } \\
\text { (Mean and S.D.) }\end{array}$ & $\begin{array}{l}\text { Test of Differences } \\
\text { between the Means }\end{array}$ \\
\hline $\begin{array}{l}E_{0} \\
P_{0} \\
E_{1}\end{array}$ & $\begin{array}{l}8 \\
8 \\
8\end{array}$ & $\begin{array}{l}14.6 \pm 3.7\left(\bar{x}_{1}\right) \\
37.9 \pm 4.0\left(\bar{x}_{2}\right) \\
47.9 \pm 5.3\left(\bar{x}_{3}\right)\end{array}$ & $\begin{array}{l}\mathbf{P}<0.001\left(\bar{x}_{2}-\bar{x}_{1}\right) \\
\mathbf{P}<0.001\left(\bar{x}_{3}-\bar{x}_{1}\right) \\
\mathbf{P}<0.001\left(\bar{x}_{3}-\bar{x}_{2}\right)\end{array}$ \\
\hline $\begin{array}{l}\mathbf{P}_{0} \\
\mathbf{P}_{\mathbf{1}}\end{array}$ & $\begin{array}{l}4 \\
4\end{array}$ & $\begin{array}{l}42 \cdot 3 \pm 3 \cdot 3\left(\bar{x}_{1}\right) \\
57 \cdot 8 \pm 3 \cdot 3\left(\bar{x}_{2}\right)\end{array}$ & $P<0.001\left(\bar{x}_{2}-\bar{x}_{1}\right)$ \\
\hline $\begin{array}{l}\mathbf{P}_{1} \\
\mathbf{E}_{\mathbf{1}}\end{array}$ & $\begin{array}{l}4 \\
4\end{array}$ & $\begin{array}{l}38 \cdot 8 \pm 5 \cdot 4\left(\bar{x}_{1}\right) \\
6 \mathrm{I} \cdot 3 \pm 5 \cdot 4\left(\bar{x}_{2}\right)\end{array}$ & $P<0.001\left(\bar{x}_{2}-\bar{x}_{1}\right)$ \\
\hline
\end{tabular}

after PCA injection. This is also evident from the fact that after the injection of Ca-EDTA the lead excretion during the second period of diuresis was greater, in relation to the 24-hour amount, than it was after PCA. The difference was significant $(P<0.01)$, and the difference between the means for lead excretion during the first and second periods of diuresis was of a smaller significance during treatment with Ca-EDTA $(\mathbf{P}<0.05)$ than with PCA $(\mathrm{P}<0.001$ ) (Table IV).

Oral therapy with PCA gave the same pattern of lead excretion as intravenous Ca-EDTA. The maxima and minima of excretion seemed to be somewhat less pronounced (Fig. 2), but the differences between the means for corresponding periods 


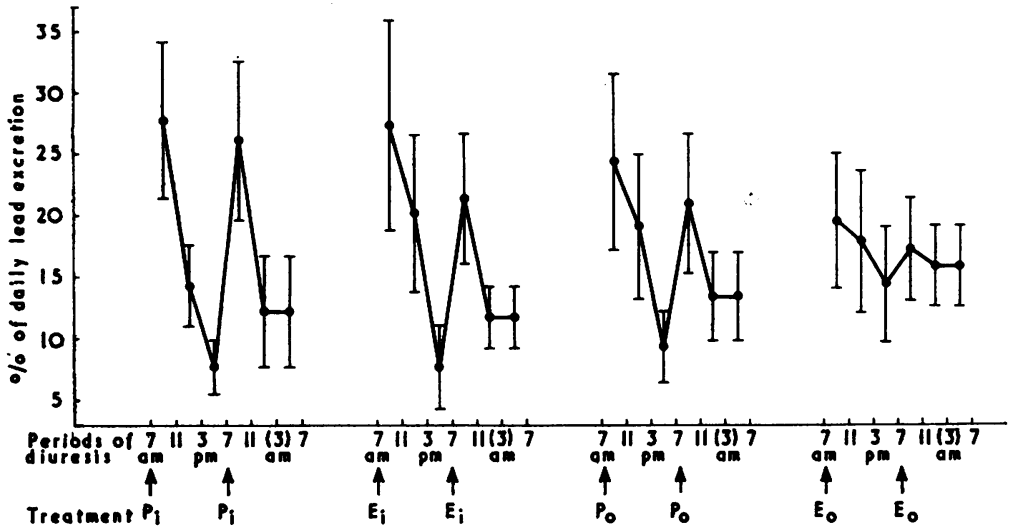

Fig. 2. Variations of lead excretion during consecutive periods of diuresis for 24 hours, induced by the different agents. The standard deviations are indicated.

TABLE IV

Variations During 24 Hours Lead Excretion Induced by Therapy with Different Agents

\begin{tabular}{|c|c|c|c|c|}
\hline Therapy & $\begin{array}{l}\text { 4-hour Periods } \\
\text { of Diuresis }\end{array}$ & No. of Observations & $\begin{array}{c}\text { Per cent of Daily Lead } \\
\text { Excretion (Mean and S.D.) }\end{array}$ & $\begin{array}{c}\text { Test of Differences between } \\
\text { the Means }\end{array}$ \\
\hline $\mathbf{P}_{\mathbf{1}}$ & $\left.\begin{array}{r}7-11 \\
11-3 \\
3-7 \\
7-11 \\
11-3 \\
3-7\end{array}\right\}$ * & $\begin{array}{l}20 \\
20 \\
20 \\
19 \\
19\end{array}$ & $\begin{array}{r}27 \cdot 8 \pm 6 \cdot 4\left(\bar{x}_{1}\right) \\
14 \cdot 3 \pm 3 \cdot 3\left(\bar{x}_{2}\right) \\
7 \cdot 7 \pm 2 \cdot 2\left(\bar{x}_{3}\right) \\
26 \cdot 1 \pm 6 \cdot 5\left(\bar{x}_{4}\right) \\
12 \cdot 2 \pm 4.5\left(\bar{x}_{5}\right)\end{array}$ & $\begin{array}{l}P<0.001\left(\bar{x}_{1}-\bar{x}_{2}\right) \\
P<0.001\left(\bar{x}_{1}-\bar{x}_{3}\right) \\
P<0.001\left(\bar{x}_{2}-\bar{x}_{3}\right) \\
P<0.001\left(\bar{x}_{4}-\bar{x}_{3}\right) \\
P<0.001\left(\bar{x}_{4}-\bar{x}_{5}\right)\end{array}$ \\
\hline $\mathbf{E}_{\mathbf{1}}$ & $\left.\begin{array}{r}7-11 \\
11-3 \\
3-7 \\
7-11 \\
11-3 \\
3-7\end{array}\right\}$ * & $\begin{array}{l}15 \\
15 \\
15 \\
15 \\
15\end{array}$ & $\begin{array}{r}27.4 \pm 8.6\left(\bar{x}_{1}\right) \\
20.2 \pm 6.4\left(\bar{x}_{2}\right) \\
7.7 \pm 3.4\left(\bar{x}_{3}\right) \\
21.4 \pm 5.3\left(\bar{x}_{4}\right) \\
11 \cdot 7 \pm 2.5\left(\bar{x}_{5}\right)\end{array}$ & $\begin{array}{l}P<0.05\left(\bar{x}_{1}-\bar{x}_{2}\right) \\
P<0.001\left(\bar{x}_{1}-\bar{x}_{3}\right) \\
P<0.001\left(\bar{x}_{2}-\bar{x}_{3}\right) \\
P<0.001\left(\bar{x}_{4}-\bar{x}_{3}\right) \\
P<0.001\left(\bar{x}_{4}-\bar{x}_{5}\right)\end{array}$ \\
\hline $\mathbf{P o}_{\mathbf{0}}$ & $\left.\begin{array}{r}7-11 \\
11-3 \\
3-7 \\
7-11 \\
11-3 \\
3-7\end{array}\right\}$ * & $\begin{array}{l}22 \\
22 \\
22 \\
23 \\
23\end{array}$ & $\begin{array}{r}24 \cdot 4 \pm 7 \cdot 2\left(\bar{x}_{1}\right) \\
19 \cdot 1 \pm 5 \cdot 9\left(\bar{x}_{2}\right) \\
9 \cdot 3 \pm 2 \cdot 9\left(\bar{x}_{3}\right) \\
21 \cdot 0 \pm 5 \cdot 7\left(\bar{x}_{4}\right) \\
13 \cdot 4 \pm 3.6\left(\bar{x}_{5}\right)\end{array}$ & $\begin{array}{l}P<0.05\left(\bar{x}_{1}-\bar{x}_{2}\right) \\
P<0.001\left(\bar{x}_{1}-\bar{x}_{3}\right) \\
P<0.001\left(\bar{x}_{2}-\bar{x}_{3}\right) \\
P<0.001\left(\bar{x}_{4}-\bar{x}_{3}\right) \\
P<0.001\left(\bar{x}_{4}-\bar{x}_{5}\right)\end{array}$ \\
\hline $\mathbf{E}_{0}$ & $\left.\begin{array}{r}7-11 \\
11-3 \\
3-7 \\
7-11 \\
11-3 \\
3-7\end{array}\right\} \star \star$ & $\begin{array}{l}16 \\
16 \\
16 \\
15 \\
15\end{array}$ & $\begin{array}{l}19.6 \pm 5.5\left(\bar{x}_{1}\right) \\
17.9 \pm 5.8\left(\bar{x}_{2}\right) \\
14.4 \pm 4.7\left(\bar{x}_{3}\right) \\
17.3 \pm 4.2\left(\bar{x}_{4}\right) \\
15.9 \pm 3.3\left(\bar{x}_{5}\right)\end{array}$ & $\begin{array}{ll}P<0.50 & \left(\bar{x}_{1}-\bar{x}_{2}\right) \\
P<0.01 & \left(\bar{x}_{1}-\bar{x}_{3}\right) \\
P<0.10 & \left(\bar{x}_{2}-\bar{x}_{3}\right) \\
P<0.10 & \left(\bar{x}_{4}-\bar{x}_{3}\right) \\
P<0.50 & \left(\bar{x}_{4}-\bar{x}_{5}\right)\end{array}$ \\
\hline
\end{tabular}

*The night periods were combined into one sample, and the mean lead excretion for this sample was divided equally between both 4-hour periods.

of diuresis were not significant. Consequently, the difference in effect between oral and intravenous PCA therapy was the same as between intravenous Ca-EDTA and intravenous PCA therapy. Thus, on some occasions after the dose of oral PCA at 7 a.m. a delay of maximal lead excretion to the second period of diuresis was observed, so that the mean for this period was significantly higher than it was during treatment with intravenous PCA $(P<0.01)$. This delay is also evident from the fact that the difference in lead excretion between the first and second periods of diuresis was of lesser 
significance during oral than during intravenous PCA treatment (Table IV). Further, after the second dose the peak of lead excretion wasnot quite as high as it was after intravenous PCA. The difference between the means is significant $(P<0.01)$. Comparing oral and intravenous PCA, there were no other significant differences between the means for lead excretion during corresponding periods of diuresis.

Oral Ca-EDTA did not produce the same variations in the 24-hour lead excretion as did the other agents, although there seemed to be a tendency towards maximal and minimal excretion during the corresponding periods of diuresis. Thus, the differences between the means for excretion during the different periods of "diuresis were not significant, except for the comparison between the first and third periods (Table IV). In individual cases the maximal excretion occurred at different times after a given dosage of oral Ca-EDTA, and in several cases there were hardly any noticeable variations in lead excretion during the 24 hours.

Effects on the Output of ALA in Urine The ALA output is a direct measure of a metabolic effect of lead poisoning (Haeger-Aronsen, 1960; Cramér and Selander, 1965). Table II shows, for each patient, the manner in which the concentration of ALA was influenced by treatment. In treatment groups 2 and 3, it is evident that there was a prompt and pronounced reduction of the ALA output. In group I, however, the results were somewhat different. Figure 3 shows the means of the ALA

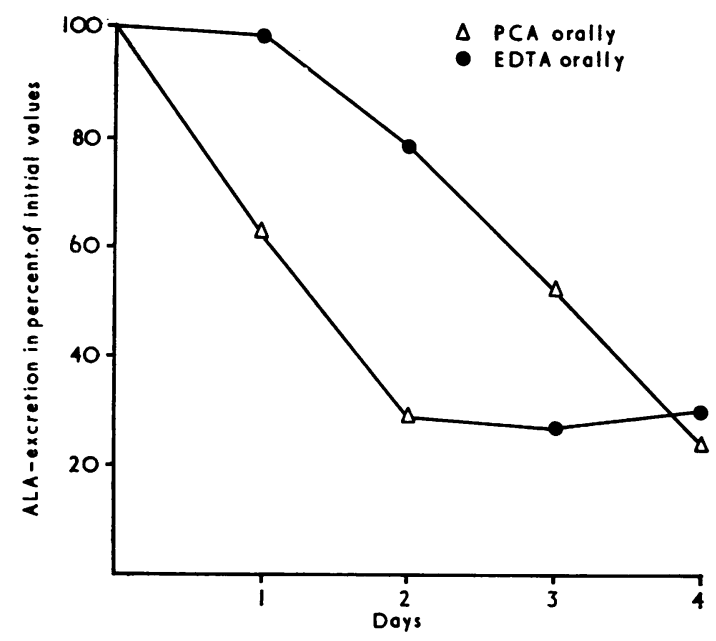

Fig. 3. Effects of oral treatment with Ca-EDTA and PCA on the ALA excretion in urine. concentrations during treatment, expressed as percentages of the initial values. When the treatment was begun with oral PCA there was a pronounced reduction of the ALA concentrations during the first day and a $70 \%$ reduction during the second day. When the treatment was started with oral Ca-EDTA the effect on ALA excretion was substantially less; no reduction occurred during the first day (it will be seen from Table II that there was an increase in two of the cases). After two days with this treatment there was only a $20 \%$ reduction of the ALA concentration. However, when treatment was continued with PCA, the result was a rapid and pronounced diminution in ALA output. It should be noted that in patient VIII there was a two-day interruption after oral Ca-EDTA treatment, during which the ALA concentration increased to 2.18 $\mathrm{mg}$./100 $\mathrm{ml}$. before PCA treatment was started.

Effects of Probenecid In four patients (IX, $\mathrm{X}, \mathrm{XI}$, and XII) a combination of PCA with probenecid for two days, with the intention of blocking the PCA excretion and thereby enhancing its effect, gave no decisive result (Table II). In patients IX and $X$ perhaps a somewhat greater lead excretion was maintained than might have been expected with PCA alone, but in the two other patients no such tendency was seen.

No side-effects were observed during the comparatively brief courses of treatment.

\section{Discussion}

As can be seen from the laboratory values and the amount of lead excreted during treatment, there were marked variations in the degree of lead poisoning among the patients (Table I). In a previous paper (Cramér and Selander, 1965) we showed that there is a very strong correlation between the ALA output in urine and the amount of lead which is excreted during a fixed course of treatment. In this respect two patients in this series (IX and XIII) seemed to be atypical, because they had a lower initial ALA concentration in relation to the total lead excretion during treatment. In patient IX this can be explained by the fact that the lead excretion was somewhat greater than usual because this patient, unlike the others, was treated only a day or two after his last exposure to lead. In patient XIII the exceptionally high diuresis may have contributed to the relatively low concentration of ALA in the urine. In the seven patients in whom a sternal puncture was performed, the changes in the bone marrow were the same as previously observed (Selander et al., 1966). Similar 
findings have been reported by David (1959), but he did not find any changes in granulocytopoiesis.

Comparable Dosages Comparing the efficiency of two ligands, in this case Ca-EDTA and PCA, which form complexes with lead in different ways, the problem of comparable dosages must be considered. As mentioned previously, only a few comparisons between Ca-EDTA and PCA have been published. In those papers the dosages were variable and in particular the question of comparable dosages was not discussed (Harris, 1958; Mosser and Bessman, 1960; Ohlsson, 1962 and 1963; Moncrieff et al., 1964; Caccuri and Pecora, 1965). A comparison based on the molecular weights makes sense only if it is known how the formation of the complexes is accomplished, for instance if one or more molecules of the agents are required for binding one molecule of lead. The metal complex formation of Ca-EDTA is well known; the ligand is multidentate, i.e., it has six donor groups and probably forms chelate with one molecule of lead. On the other hand, very little is known about the complex formation of penicillamine, as is the case for other thiol-compounds. Mononuclear $\left(\mathrm{Pb}(\mathrm{PCA})_{\mathrm{n}}\right)$ as well as multinuclear $\left(\left(\mathrm{Pb}_{\mathrm{p}}(\mathrm{PCA})_{\mathrm{q}}\right)\right.$ complex formation is conceivable. Considering that the PCA molecule is 3-dentate, it is probable that chelate is formed. However, the $-S^{-}$group can favour 1-dentate coordination owing to its pronounced capacity for binding lead. The coexistence of different types of complexes is also possible (Österberg, I967, personal communication). Another method of comparing the effects of two agents, which might have been the most appropriate in this case, is to give both agents in the highest possible dosage without causing serious side-effects, but, since that is not without certain risks, it was deemed inadvisable in this study.

Accordingly it was decided to base the comparison on equal quantities by weight, using $2 \mathrm{~g}$. Ca-EDTA a day intravenously as a reference dosage, since that is a common dosage which also is approximately the maximal advisable dosage for daily treatment. Such a comparison has its deficiencies and it ought to be to the disadvantage of PCA, which can be given in substantially higher dosages without considerable risk of more severe side-effects.

Therapeutic Effect For a comparison of the effects of the agents on lead excretion, the percentage of total excretion was chosen as the measure, instead of the increase in lead concentration in the urine. This was because the initial values for lead concentration are not particularly well correlated with the degree of lead poisoning (Cramér and Selander, 1965).

Intravenous Ca-EDTA and PCA With intravenous treatment the difference in effect between Ca-EDTA and PCA was not as evident in the two most intoxicated patients as in the other two. A possible explanation is that Ca-EDTA, to a greater degree than PCA, is able to form complexes with lead that is less accessible. This difference is then less noticeable the more intoxicated the patients are, i.e., the more 'easily accessible' lead there is. The satisfactory effect of both these agents on lead excretion and their ability to produce a rapid and pronounced reduction of ALA output seem to make it immaterial which should be chosen for intravenous treatment. However, it is not known whether there are any important long-term differences in their effectiveness. This could only be determined by a long-term follow-up of patients who were no longer exposed to lead after the end of treatment. From our present knowledge of the side-effects of these drugs, PCA should probably be preferred.

Similar effects on lead excretion during intravenous treatment with Ca-EDTA and PCA have been reported in four cases by Ohlsson (1962). However, that investigation was done in a different way from this study, and a direct comparison of the results is not possible. Additional reports comparing the effects of intravenous Ca-EDTA and PCA have not been found in the literature.

The lead complexes formed were excreted by the kidneys at approximately the same rate, which is evident from the fact that the maximal and minimal lead excretion appeared within the same period after the agents were given (Fig. 2). However, the delay in excretion of the lead complexes, which was observed in some cases after Ca-EDTA, but not after PCA, has a practical significance primarily in diagnostic mobilization tests. Thus, after a test dosage of intravenous PCA, collection of urine for four hours is sufficient whereas the urine must be collected for eight hours after Ca-EDTA to ensure obtaining maximal lead excretion. Teisinger and Srbová (1959) found a maximal lead concentration in the urine three to nine hours after intravenous Ca-EDTA, but the investigation was done on spot samples and not with fractionated quantitative collection of urine. The value of mobilization tests with quantitative urinary collection for 24 hours has been emphasized by Rieders (1960). However, the author is of the opinion that the collection of urine during a much shorter period should suffice, and he suggested investigations on this subject. 
Intravenous and Oral PCA This comparison showed that, although lead excretion following intravenous PCA was higher than following oral PCA, the latter caused a substantial excretion of lead and therefore oral therapy is sufficient in most cases and further, that oral PCA must have been absorbed to a great extent. This is true provided that the increased lead excretion was not due to a resorption of PCA-lead complex from the gastrointestinal tract. That this could not have occurred in any quantity is evident from the beneficial effect of the treatment on the metabolic manifestation of lead poisoning expressed as the ALA output in urine.

Thus, on average, the ALA concentration was reduced by $70 \%$ as early as the first two days after treatment with oral PCA (Fig. 3). In a previous paper it was shown that the concentrations of ALA in urine and of lead in blood decreased in parallel fashion during this treatment. Such a rapid effect on the ALA output during treatment with oral PCA has also been reported by Goldberg et al. (1963) and by Caccuri and Pecora (1965). Not only was the major part of the administered PCA absorbed but it was also absorbed rapidly, which is evident from the fact that after a given dosage the peak of lead excretion was registered within four hours in the same way as after the intravenous injection of PCA and Ca-EDTA (Fig. 2). The delay in maximal lead excretion to the second period of diuresis observed in some patients, as was the case after the intravenous injection of Ca-EDTA, was here probably not dependent upon the excretion rate of the lead complex by the kidneys. As has been seen, there was no such delay of maximal lead excretion after intravenous PCA, and the formed PCA-lead complex should reasonably be excreted at the same rate whether PCA was given intravenously or orally. Consequently, the delay after oral administration of PCA probably depended on a somewhat slower absorption in those patients. It means, however, that urine must be collected for eight hours during a mobilization test with oral PCA, in the same way as with intravenous Ca-EDTA. Ohlsson (1963) reported good results with a mobilization test of this type. He administered $450 \mathrm{mg}$. of PCA at bedtime, and the lead concentration in the urine collected during the night, i.e., roughly during eight hours, was compared with that in the urine voided immediately before the PCA capsules had been taken.

The lesser effect of oral PCA on lead excretion compared with that of intravenous PCA and Ca-EDTA in the same dosages was obvious. The effect was nevertheless quite satisfactory and the great advantages of effective oral treatment are evident. The same conclusions were expressed by Harris (1958), and he also suggested studies comparing oral PCA and Ca-EDTA. A different view of the efficacy of oral PCA was held by Mosser and Bessman (1960). After treating two children the authors considered that they had shown the efficacy of oral PCA to be low compared with that of intravenous Ca-EDTA. However, the comparison was based on molecular weights and accordingly, by weight, only one-third to one-half as much PCA as Ca-EDTA was given. A statement difficult to understand is that PCA would be more toxic than Ca-EDTA when given in the same amounts. No support for this statement was presented. Satisfactory experience in the use of PCA in the treatment of children is reported by, among others, Moncrieff et al. (1964) from a study of 20 patients. These authors emphasize the great advantage of satisfactory oral treatment in paediatric practice, but they recommend intravenous Ca-EDTA in the more severe cases of lead poisoning. In our experience, intravenous PCA is a quite adequate alternative in those cases. A consideration of the risks of sideeffects may decide the choice of treatment.

Oral $C a-E D T A$ The unsatisfactory effect of oral Ca-EDTA on lead excretion was not surprising considering its poor absorption. On the contrary, more lead was excreted than was expected in view of this poor absorption and in proportion to the effect of intravenous Ca-EDTA. This might be explained by Ca-EDTA binding lead easily available in the intestines and then for the most part being absorbed as Ca-EDTA-lead complex, which has been shown, both in humans and in animal experiments, to be resorbable in considerable amounts (Mosey et al., cited by Sidbury et al., 1953; Rieders, 1954; Shapiro, 1960). This question has been discussed by several authors and frequently their opinions differ. Byers (1959a) and Rieders (1960) were convinced that the increased lead excretion in the urine depends on an absorption of Ca-EDTA-lead complex and they consider oral Ca-EDTA to be contraindicated. Kehoe (1955) was of the same opinion, and he warned against using the agent, above all as a prophylactic during lead-exposed work. On the other hand, Manville and Moser (1955), Bell and his colleagues (1956), and Williams et al. (1962) reported good results after treatment with oral Ca-EDTA and they did not think that the absorption of Ca-EDTA-lead complex was substantial.

An intermediate attitude was taken by Shiels, Thomas, and Kearley (1956), who considered the 
agent to have a certain effect, but that treatment, in connexion with lead exposure, probably caused an absorption of Ca-EDTA-lead complex. The positive opinion regarding the effect of oral Ca-EDTA, often expressed in the papers mentioned above, is hard to understand. With regard to the dosages of Ca-EDTA, the lead excretion obtained was of approximately the same magnitude as in this investigation, despite the fact that the average values for lead concentration in the blood were constantly significantly higher than in the present investigation. Thus, Williams and his colleagues (I962) reported an average lead excretion of $14.32 \mathrm{mg}$. after seven days' treatment with $4 \mathrm{~g}$. Ca-EDTA daily to patients with a lead concentration in the blood of 100 to $170 \mu \mathrm{g} . / 100 \mathrm{ml}$. In comparison it can be mentioned that the only patient (IX) in this study who had a similar concentration of lead in the blood (100 $\mu \mathrm{g}$./100 ml.) excreted $9.64 \mathrm{mg}$. of lead during 24 hours on a treatment of $2 \mathrm{~g}$. PCA orally (Table II). Neither were the effects on lead concentration in the blood and on the output of coproporphyrins in the urine convincing, and not infrequently there was an initial increase of values during treatment. These facts are in agreement with the observation in this investigation that the effect on the concentration of ALA in the urine was poor also when the lead excretion in the urine seemed to be relatively good, as for example in patient VI. The same experience was reported by Tishkoff, Granville, Rosen, and Dameshek (1958).

These unsatisfactory effects on the concentration of lead in the blood, and on the output of coproporphyrins and of ALA in the urine, in spite of a maintained increase of lead excretion, are observations which support the idea that oral Ca-EDTA binds lead available in the intestines, after which this Ca-EDTA-lead complex is absorbed. To what extent this occurs, of course depends on how much lead there is available. The amount swallowed during an exposure may well vary from individual to individual. Exclusion from lead exposure for some time before treatment with oral Ca-EDTA may seem to be of some value but must not be overestimated, as there is a likelihood that swallowed lead particles may remain on the intestinal wall for a considerable time. Prophylactic treatment during continued lead exposure is therefore contra-indicated.

Why do not analogous conditions seem to be valid for treatment with oral PCA? There are various possible reasons. As we know, PCA is rapidly absorbed and, if this absorption occurs relatively proximally in the gastro-intestinal tract, the opportunity to form complexes with swallowed lead is diminished. Further, it is not known if PCA-lead complexes are formed in the intestinal environment, and, if so, whether or not they are absorbed. The results presented here speak against its occurrence in any marked degree. As can be seen from Fig. 2 and Table IV, oral Ca-EDTA in contrast to oral PCA produced a hardly noticeable variation in the 24 hours' lead excretion, indicating a slow absorption of the agent. Foreman (1960) has also shown that only about $2 \%$ was absorbed within 2I hours. For this reason the conditions are favourable for contact with lead in the greater part of the gastro-intestinal tract.

An observation of interest in this connexion is that it has been possible by autoradiography to demonstrate that lead injected intravenously into rats is concentrated, among other places, in the intestinal wall of the caecal region (Johansson, 1964).

An additional factor which may be of essential importance is the $p \mathrm{H}$ in the gastro-intestinal tract. Thus, Foreman (1960) considered it likely that Ca-EDTA is precipitated at the low $p H$ in the stomach and then only slowly dissolved as it passes through the intestines.

An observation in this study which may be cited in support of this suggestion is that the only patient (VII) who showed a more pronounced maximum for lead excretion after a dosage of oral Ca-EDTA, as an indication of more rapid absorption, had had a subtotal gastric resection (Billroth II) performed.

Probenecid in Combination with PCA Capsules Three different effects were possible: (I) A blocking effect on the renal excretion of PCA. In that case the lead excretion ought to be increased because a higher concentration of PCA was maintained in the body. (2) A blocking of PCA excretion and of the excretion of the PCA-lead complexes. This should have reduced the figures for lead in urine. After probenecid treatment had been stopped an increase in lead output would be expected. (3) No blocking effect of probenecid.

In none of the four patients was a smaller lead excretion noted than was expected, nor was there any increase in excretion when treatment with probenecid was stopped. The tendency in subjects IX and $\mathrm{X}$ to a maintained increase in lead excretion during the administration of probenecid was not sufficient to conclude that probenecid had a blocking effect on PCA excretion.

Thus, the results are in favour of the third alternative, i.e., probenecid has no effect on the renal excretion of PCA and PCA-lead complexes, but further investigation would be of interest. 
Thanks are due to Dr. R. Österberg for valuable discussions on the problem of lead-ligand complex formation.

Skilful laboratory aid was given by Miss Birgitta Börjesson and Miss Gunilla Mandorf.

\section{REFERENCES}

Bell, R. F., Gilliland, J. C., Boland, J. R., and Sullivan, B. R. (1956). Arch. industr. Hlth, 13, 366.

Bessman, S. P., Ried, H., and Rubin, M. (1952). Med. Ann. D.C., $21,312$.

Boulding, J. E., and Baker, R. A. (1957). Lancet, 2, 985.

Byers, D. H. (1959a). Industr. Med. Surg., 28, 133.

Byers, R. K. (1959b). Pediatrics, 23, 585.

Caccuri, S., and Pecora, L. (1965). Minerva med., (Parte sci.) $56,4543$.

Cramér, K., and Selander, S. (1965). Brit. F. industr. Med., 22, 311 .

David, A. (1959). Arch. Gewerbepath. Gewerbehyg., 17, 329.

Foreman, H. (1960). In Metal-Binding in Medicine, Proc. Symp. Hahnemann Medical College, Philadelphia. Ed. Seven, M. J., p. 82. Lippincott, Philadelphia.

- Hardy, H. L., Shipman, T. L., and Belknap, E. L. (1953). Arch. industr. Hyg., 7, 148.

Goldberg, A., Smith, J. A., and Lochhead, A. C. (1963). Brit. med. $\mathcal{F}$., $1,1270$.

Haeger-Aronsen, B. (1960). Scand. F. clin. Lab. Invest., 12, Suppl. 47.

Harris, C. E. C. (1958). Canad. med. Ass. F., 79, 664.

Johansson, L-G. (I964). Personal communication.

Kehoe, R. A. (1955). F. Amer. med. Ass., 157, 341.

Leckie, W. J. H., and Tompsett, S. L. (1958). Quart. F. Med., 27,65 .

Manville, I. A., and Moser, R. (1955). Arch. industr. Hlth, 12,528 .
Moncrieff, A. A., Koumides, O. P., Clayton, B. E., Patrick, A. D., Renwick, A. G. C., and Roberts, G. E. (1964). Arch. Dis. Childh., 39, I.

Mosser, R. S., and Bessman, S. P. (1960). Bull. Sch. Med. Maryland, 45, 47.

Ohlsson, W. T. L. (1962). Brit. med. F., r, 1454 .

(1963). Occup. Hlth Rev., 15, no. 3, p. 14.

Perol, R., Graveleau, J., Potter, M., and Morin, M. (1962). Sem. Hôp. Paris, 38, 3342.

Rieders, F. (1954). Fed. Proc., 13, 397.

- (1960). In Metal-Binding in Medicine, Proc. Symp. Hahnemann Medical College, Philadelphia. Ed. Seven, M. J., p. 143. Lippincott, Philadelphia.

$\longrightarrow$, and Breiger, H. (1955). Proceedings of the Seventh Annual Meeting of the American Academy of Occupational Medicine, pp. 83-84.

-, Dunnington, W. G., and Breiger, H. (1955). Industr. Med. Surg., 24, 195.

Selander, S., Cramér, K., and Hallberg, L. (1966). Brit. F. industr. Med., 23, 282.

Shapiro, R. (1960). In Metal-Binding in Medicine, Proc. Symp. Hahnemann Medical College, Philadelphia, Ed. Seven, M. J., p. 249. Lippincott, Philadelphia.

Shiels, D. O., Thomas, D. L. G., and Kearley, E. (1956). Arch. industr. Hlth., 13, 489.

Sidbury, J. B., Jr., Bynum, J. C., and Fetz, L. L. (1953). Proc. Soc. exp. Biol. (N.Y.)., 82, 226.

Srbová, J., and Teisinger, J. (1957). Arch. Gewerbepath. Gewerbehyg., 15, 572.

Teisinger, J., and Srbová, J. (1956). Ibid., 14, 579.

$\longrightarrow$, and - (1959). Brit. F. industr. Med., 16, 148.

Tishkoff, G. H., Granville, N. B., Rosen, R., and Dameshek, W. (1958.). Acta haemat. (Basel), 19, 32 I.

Williams, J. D., Matthews, G. A., and Judd, A. W. (1962). Brit. F. in tustr. Med., 19, 2 I 1. 
APPENDIX

\begin{tabular}{|c|c|c|c|}
\hline Patient & Occupational History & Previous Lead Poisoning & Present Symptoms \\
\hline I & Ship-breaking yard, 4 yrs. & $\begin{array}{l}\text { Four times. Last treatment } 4 \text { mths } \\
\text { ago }\end{array}$ & Pronounced tiredness, metallic taste \\
\hline II & Storage battery factory, $2 \mathrm{mths}$ & None & $\begin{array}{l}\text { Loss of appetite and weight, head- } \\
\text { ache, muscle cramps in the } \\
\text { forearms }\end{array}$ \\
\hline III & Storage battery factory, I mth & None & Tiredness \\
\hline IV & Ship-breaking yard, 6 yrs & $\begin{array}{l}\text { Six times. Last treatment } 6 \mathrm{mths} \\
\text { ago }\end{array}$ & Denies symptoms \\
\hline V & Ship-breaking yard, 6 yrs & $\begin{array}{l}\text { Seven times. Last treatment } 2 \text { mths } \\
\text { ago }\end{array}$ & Denies symptoms \\
\hline VI & $\begin{array}{l}\text { Storage battery factory during } 4 \\
\text { mths, } 2 \text { yrs ago. Same job since } \\
\text { I year }\end{array}$ & Once 2 yrs ago. Refused treatment & Nausea, abdominal colic \\
\hline VII & Ship-breaking yard, $2 \frac{1}{2}$ yrs & $\begin{array}{l}\text { Three times. Last treatment } \mathrm{I} \text { yr } \\
\text { ago }\end{array}$ & $\begin{array}{l}\text { Tiredness, irritability, muscle } \\
\text { cramps in the calves, abdominal } \\
\text { colic, constipation alternating with } \\
\text { diarrhoea }\end{array}$ \\
\hline VIII & Ship-breaking yard, $3 \mathrm{mths}$ & None & Pronounced tiredness, headache \\
\hline IX & $\begin{array}{l}\text { Previously working in a motorcar } \\
\text { workshop smothering bodies with } \\
\text { lead-containing solder. Last } 5 \text { yrs } \\
\text { metal-painting using an acetylene } \\
\text { torch. Since } 3 \text { wks metallizing the } \\
\text { inside of a funnel }\end{array}$ & Once ro yrs ago & $\begin{array}{l}\text { Tiredness, dizziness, headache, } \\
\text { metallic taste, nausea }\end{array}$ \\
\hline $\mathbf{X}$ & $\begin{array}{l}\text { Scrap-metal worker, } 5 \text { yrs } \\
\text { Ship-breaking yard last } 3 \text { mths }\end{array}$ & None & $\begin{array}{l}\text { Pronounced tiredness, headache, } \\
\text { muscle cramps in the forearms and } \\
\text { calves, metallic taste, nausea, loss } \\
\text { of appetite and weight, vomiting, } \\
\text { abdominal colic }\end{array}$ \\
\hline $\mathbf{X I}$ & Ship-breaking yard, 4 yrs & $\begin{array}{l}\text { Five times. Last treatment } 9 \mathrm{mths} \\
\text { ago }\end{array}$ & $\begin{array}{l}\text { Pronounced tiredness, irritability, } \\
\text { metallic taste, loss of appetite and } \\
\text { weight, abdominal colic, constipa- } \\
\text { tion alternating with diarrhoea }\end{array}$ \\
\hline XII & Ship-breaking yard, $7 \frac{1}{2}$ yrs & $\begin{array}{l}\text { Eight times. Last treatment } 5 \mathrm{mths} \\
\text { ago }\end{array}$ & Denies symptoms \\
\hline XIII & Ship-breaking yard, 2 yrs & Once I yr ago & $\begin{array}{l}\text { Pronounced tiredness, irritability, } \\
\text { muscle cramps in the forearms }\end{array}$ \\
\hline XIV & Ship-breaking yard, 8 yrs & $\begin{array}{l}\text { Nine times. Last treatment } 8 \mathrm{mths} \\
\text { ago }\end{array}$ & Tiredness, nausea, diarrhoea \\
\hline XV & $\begin{array}{l}\text { Storage battery factory, I yr. At first } \\
\text { in Yugoslavia, last } 2 \text { wks in } \\
\text { Sweden }\end{array}$ & None & $\begin{array}{l}\text { Denies symptoms. (The patient had } \\
\text { the idea that he could be sent back } \\
\text { to his home country if being } \\
\text { considered unable to work) }\end{array}$ \\
\hline XVI & Storage battery factory, I yr & Once $2 \mathrm{mths}$ ago & $\begin{array}{l}\text { Tiredness, metallic taste, loss of } \\
\text { appetite }\end{array}$ \\
\hline
\end{tabular}

